\title{
Probiotics ameliorate pioglitazone-associated bone loss in diabetic rats
}

\author{
Ahmad Gholami ', Mohammad Hossein Dabbaghmanesh², Younes Ghasemi ${ }^{1}$, Pedram Talezadeh², \\ Farhad Koohpeyma ${ }^{2}$ and Nima Montazeri-Najafabady²*
}

\begin{abstract}
Background: Pioglitazone, as a PPAR gamma agonist, is used for the management of type 2 diabetes mellitus. Nevertheless, evidence showed that the therapeutic modulation of PPAR gamma activity using pioglitazone might be linked with bone mass reduction and fracture risk in type 2 diabetes mellitus patients. The objective of the current research was to inspect the preventive role of some types of probiotic strains, including (Lactobacillus acidophilus, Lactobacillus reuteri, Lactobacillus casei, Bifidobacterium longum, and Bacillus coagulans) against pioglitazone-induced bone loss.

Methods: Streptozotocin $(60 \mathrm{mg} / \mathrm{kg}$ ) was administered for diabetes induction. Diabetic rats were fed orally with pioglitazone $(300 \mathrm{mg} / \mathrm{kg})$ and probiotics $\left(1 \times 10^{9} \mathrm{CFU} / \mathrm{ml} /\right.$ day) alone and in combination for four weeks. Dual-energy $X$-ray absorptiometry (DXA) was used to assess BMD, BMC, and area of the femur, spine, and tibia at the end of the experiment. Serum glucose, serum calcium (Ca), alkaline phosphatase (ALP), phosphorus (P), Blood urea nitrogen $(B \cup N)$, creatinine, and urine calcium were also analyzed.

Results: Administration of pioglitazone and probiotics alone and, in combination, significantly reduced elevated blood glucose. Pioglitazone treatment significantly increased urinary calcium and BUN and decreased ALP and creatinine. Co-treatment of probiotics with pioglitazone significantly decreased urinary calcium, creatinine, and ALP. Pioglitazone showed detrimental effects on femur-BMD, whereas treatment with probiotics remarkably ameliorated these effects. Among the tested probiotics, Bifidobacterium longum displayed the best protective effects on pioglitazone-induced bone loss in diabetic rats.
\end{abstract}

Conclusion: This study suggests probiotic supplementation in diabetic patients on pioglitazone regime could be considering as an excellent strategy to ameliorate bone loss induced by pioglitazone.

Keywords: Probiotic, Pioglitazone, Type 2 diabetes, Bone

\section{Background}

According to WHO, about 422 million people had diagnosed diabetes mellitus, while the number of diabetic patients in 1980 was 180 million [1]. The occurrence of

\footnotetext{
*Correspondence: montazerin@sums.ac.ir

2 Endocrinology and Metabolism Research Center, Shiraz University of Medical Sciences, Shiraz, Iran

Full list of author information is available at the end of the article
}

type 2 diabetes (T2DM) is growing, accompanied by the extension of the obesity epidemic [2]. In uncontrolled or poorly controlled conditions, T2DM triggers severe systemic problems, including visual loss, neuropathy, renal damage, and a shortened life hope [3]. Both types of diabetes (T1DM and T2DM) are accompanying with low bone mineral density (BMD) and a high risk of bone fracture, especially at the hip due to osteoblastic dysfunction [4].

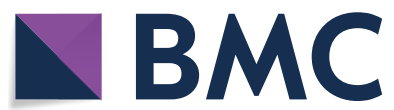

(c) The Author(s) 2020. This article is licensed under a Creative Commons Attribution 4.0 International License, which permits use, sharing, adaptation, distribution and reproduction in any medium or format, as long as you give appropriate credit to the original author(s) and the source, provide a link to the Creative Commons licence, and indicate if changes were made. The images or other third party material in this article are included in the article's Creative Commons licence, unless indicated otherwise in a credit line to the material. If material is not included in the article's Creative Commons licence and your intended use is not permitted by statutory regulation or exceeds the permitted use, you will need to obtain permission directly from the copyright holder. To view a copy of this licence, visit http://creativecommons.org/licenses/by/4.0/. The Creative Commons Public Domain Dedication waiver (http://creativecommons.org/publicdomain/zero/1.0/) applies to the data made available in this article, unless otherwise stated in a credit line to the data. 
The insulin-sensitizing thiazolidinediones (TZDs) have complemented the conventional management approaches for diabetes, such as diet, exercise, and metformin [5]. Pioglitazone and rosiglitazone are two main peroxisome proliferator-activated receptor-r (PPAR-r) thiazolidinediones, which are considered as oral glucose-lowering antidiabetic agent [6]. Long-term intake of both TZDs can lead to bone loss, and the risk of bone fractures has increased significantly in women who take these medications during T2DM [7]. Some meta-analyses of randomized clinical trials revealed that pioglitazone and rosiglitazone treatment is connected to an increased risk of fractures in all T2DM patients, especially young women [8-10]. Also, a longitudinal observational cohort study using data from the Action to Control Cardiovascular Risk in Diabetes (ACCORD) trial bone ancillary study showed that the use of rosiglitazone (or if available pioglitazone) is linked with increased bone fracture risk in women (but not in men) [11]. It seems that TZDs trigger differentiation of some stem cells into adipocytes rather than osteoblasts, causing lowered bone formation and enhanced bone resorption [12].

Recent studies have shown that probiotic bacteria have anti-T2DM effect for controlling the glucose levels [13, 14]. It is supposed that their beneficial effect is related to many internal mechanisms, including the skeletal system beyond the control of blood glucose [15]. In a previous study, we reported that some types of probiotics could improve bone formation, reduced bone resorption, and changes in the microstructure of the femur in the ovariectomized-induced bone loss rat model $[16,17]$. Dar et al. revealed that the administration of lactobacillus acidophilus for 12 weeks could attenuate bone loss and improve the mechanical bone strength in streptozotocininduced diabetic rats with no impacts on glucose concentration [18].

This study aimed to inspect the supportive role of some types of probiotic strains containing (Lactobacillus acidophilus, Lactobacillus reuteri, Lactobacillus casei, Bifidobacterium longum, and Bacillus coagulans) on the bone mass, BMD, and bone turnover markers in pioglitazonetreated rats.

\section{Methods}

\section{Bacterial isolation and formulation}

The probiotics were isolated from traditional fermented dairy products produced in Iran, according to Montazeri et al. [16]. Briefly, $10 \mathrm{~g}$ of each dairy samples were homogenized, serially diluted, and cultured on tryptone soya agar (TSA) medium. Then, for counting the number of Lactobacillus, Streptococcus, and Bifidobacterium, the Lactobacillus Streptococcus (LS) Differential medium was used, and for specific separation of Lactobacilli the de MAN, ROGOSA and SHARPE (MRS) agar, and for Bifidobacteria BFM agar was applied. After 3 days of cultivation at $37{ }^{\circ} \mathrm{C}$ under anaerobic conditions, the final characterization was done based on Bergey's Manual of Systematic Bacteriology. Their cultural, morphological, and biochemical features of each bacterium were joined to each isolate. For formulation, the strains were sub-cultured in TSA medium, maintained overnight at $37^{\circ} \mathrm{C}$ and freeze-dried. Before use, the strains were suspended in PBS ( $\mathrm{pH}$ 7.4) and stirred for $20 \mathrm{~min}$. This probiotic solution was made ready for animal feeding. The final concentration of probiotic supplements in each interval was $1 \times 10^{9} \mathrm{CFU} / \mathrm{mL}$.

\section{Experimental design}

A total of 56 adult female Sprague-Dawley rats (1214 weeks old and weighing $200 \pm 20$ g) were obtained from the Laboratory Animal Center of Shiraz University of Medical Sciences. The animals were retained under natural housing laboratory settings (room temperature with the relative humidity of $60 \pm 5 \%$, temperature of $23 \pm 2{ }^{\circ} \mathrm{C}$, and $12 \mathrm{~h} / 12 \mathrm{~h}$ light/dark cycles) and were fed a normal pellet diet (rodent chow; Behparvar Co., Tehran, Iran) and water ad libitum. Rodent chow compositions are as follows: Crude protein $23 \%$, crude fat $3.5 \%$, crude fiber $4.5 \%$, ash $10 \%$, calcium $0.95-1 \%$, phosphorus $0.65-0.7 \%, \mathrm{NaCl} 0.5 \%$, lysine $1.15 \%$, methionine $0.33 \%$, threonine $0.72 \%$, tryptophan $0.25 \%$, cysteine $0.3 \%$ ). Animals were adapted to the room for one week. Type 1 diabetes was prompted by streptozotocin inoculation $(60 \mathrm{mg} / \mathrm{kg})$. A sterile solution of Streptozotocin (STZ) (Sigma-Aldrich Company, Germany) in a $0.1 \mathrm{M}$ solution of sodium citrate $(\mathrm{pH}=4.5)$ was made and injected peritoneally. Then, the stimulation of diabetes was confirmed using fasting blood glucose samples. After that, the rats were randomly distributed into eight groups $(n=7$ per group) as follow: Group 1, Control (healthy and nondiabetic rats); Group 2, Diabetic; Group 3, pioglitazone $(30 \mathrm{mg} / \mathrm{kg} /$ day); Group 4, pioglitazone $(30 \mathrm{mg} / \mathrm{kg} /$ day) + Lactobacillus acidophilus; Group 5, pioglitazone (30 mg/kg/day) + Lactobacillus casei; Group 6, pioglitazone $(30 \mathrm{mg} / \mathrm{kg} /$ day $)+$ Bacillus coagulans; Group 7, pioglitazone $(30 \mathrm{mg} / \mathrm{kg} /$ day $)+$ Bifidobacterium; Group 8 , pioglitazone (30 $\mathrm{mg} / \mathrm{kg} /$ day $)+$ Lactobacillus reuteri . The rats in groups $3,4,5,6$, and 7 were fed orally by gavage with $1 \mathrm{~mL}\left(1 \times 10^{9} \mathrm{CFU} / \mathrm{ml} /\right.$ day $)$ of probiotics for 4weeks. The rats in groups 1 and 2 were fed with $1 \mathrm{~mL}$ PBS. All animal experiments were following the National Institutes of Health guide for the care and use of laboratory animals (NIH Publications No. 8023, revised 1978) and approved by the Ethical Committee of Shiraz University of Medical Sciences (97-01-33-18906). 


\section{Oophorectomy}

The ovary of adult female rats was removed bilaterally under anesthesia by ketamine $10 \%(100 \mathrm{mg} / \mathrm{kg}$, Alfasan, Netherlands) and xylazine $2 \%(10 \mathrm{mg} / \mathrm{kg}$, Alfasan, Netherlands). Both ovaries were detached in all groups with surgery, except for the control group after joining of the uterine horn through a midline longitudinal incision.

\section{Dual-energy X-ray absorptiometry parameters measurements}

In order to assess the area, bone mineral content (BMC), and bone mineral density (BMD) of femur, spine, and tibia, Dual-energy X-ray absorptiometry (DXA) scans were applied on a Discovery QDR, USA device with Hologic instrument via the particular software for small animals at the experiment termination. At first, we set up the RAT STEP PHANTOM (Hologic P/N010-0758Rev.004) scan. In this method, when the system motion was completed, we centered the STEP PHANTOM on the table along the long axis of the laser with the cross-hair $3 / 4$ " $(2 \mathrm{~cm})$ of the right edge of the thinnest step. Then we pressed a continue button to start the scan. BMC in grams, bone area (BA) in square centimeters, and BMD in $\mathrm{g} / \mathrm{cm}^{2}$ were measured.

\section{Biochemical parameters measurement}

All the rats were sedated with ketamine and xylazine solution intraperitoneally and sacrificed using thiopental $(100 \mathrm{mg} / \mathrm{kg})$ at the experiment termination. Blood samples were collected in chilled non-heparinized tubes to clot at room temperature by cardiocentesis. The blood samples were centrifuged (3500 rpm at $4{ }^{\circ} \mathrm{C}$ for $20 \mathrm{~min}$ ) and the separated sera were evaluated for biochemical indicators, comprising serum glucose, serum calcium $(\mathrm{Ca})$, serum phosphorus (P), alkaline phosphatase (ALP), BUN, creatinine and urinary calcium by using a spectrophotometric method (BT 1500 Auto-analyzer). Urinary calcium was collected by using a metabolic cage.

\section{Statistical analysis}

Statistical tests were conducted using IBM $\odot$ SPSS $\odot$ Statistics v 22.0 for Windows. Data are displayed as mean \pm SD. Variation of biochemical parameters (serum glucose, $\mathrm{Ca}$, P, ALP, BUN, creatinine, and urinary calcium) and bone densitometry parameters (BMD, BMC, and Area) between groups were analyzed using one-way ANOVA. Tukey post hoc analysis was executed when the outcomes of ANOVA indicated significance $(\mathrm{P} \leq 0.05)$.

\section{Results}

Isolation, identification, and characterization of bacterial strains

Despite the isolation of more than 36 bacterial strains, in this research, five bacterial strains which have appropriate probiotic properties were selected. Their physiological and biochemical characteristics were mentioned in supplementary data 1 . Based on the standard references and the morphological characteristics of isolated strains, the probiotics were recognized and characterized as Lactobacillus acidophilus, Lactobacillus reuteri, Lactobacillus casei, Bifidobacterium longum and Bacillus coagulans (Additional file 1: Table S1).

\section{Effects of probiotics on biochemical parameters}

Biochemical parameters considered for testing probiotics in this study were serum glucose, $\mathrm{Ca}, \mathrm{P}, \mathrm{ALP}, \mathrm{BUN}$, creatinine, and urinary calcium (Fig. 1).

\section{Serum glucose}

As demonstrated in Fig. 1A, glucose levels significantly reduced after administration of $\mathrm{STZ}$ compared to the control group. Blood glucose concentration in the pioglitazone group was significantly lower than the STZ group. Bifidobacterium sp. and Bacillus coagulans significantly decreased the glucose concentrations in rats compared to the STZ group. Bifidobacterium sp. significantly reduced the serum glucose concentrations more than pioglitazone in diabetic rats. No significant changes in serum glucose concentrations were detected for other probiotic strains compared to STZ and pioglitazone groups.

\section{Serum calcium}

As demonstrated in Fig. 1B, no significant differences in terms of serum calcium concentration between treated groups and control were found.

\section{Serum phosphorus}

Similar to calcium, no changes were seen in the serum phosphorus concentration between treated groups and control (Fig. 1C).

\section{Serum alkaline phosphatase (ALP)}

Pioglitazone meaningfully declined the serum ALP in comparison with the control group. Interestingly, Lactobacillus acidophilus, Lactobacillus casei, Lactobacillus reuteri, Bifidiobacter, and Bacillus coagulans reduced the serum ALP in comparison to the STZ group. Among the groups treated with probiotics, only Bacillus coagulans significantly decreased ALP concentration compared to the pioglitazone group (Fig. 1D).

\section{Blood urea nitrogen (BUN)}

In the pioglitazone group, BUN concentration was significantly elevated in comparison with the control group. Again, BUN values were significantly augmented in all groups in comparison with the STZ group, except for the Bacillus coagulans group (Fig. 1E). 


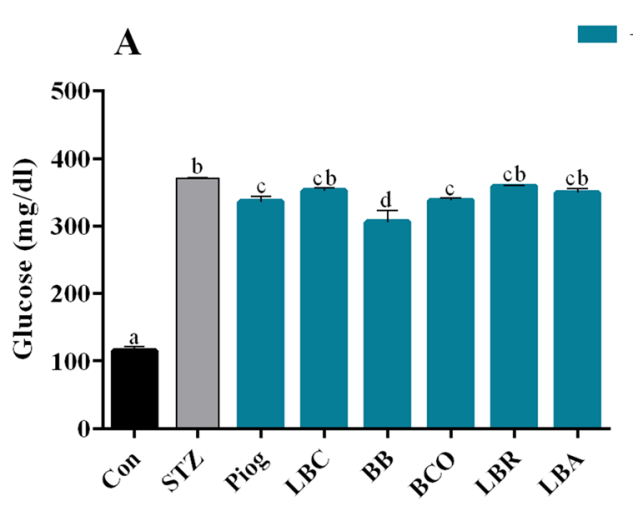

+ STZ

\section{B}

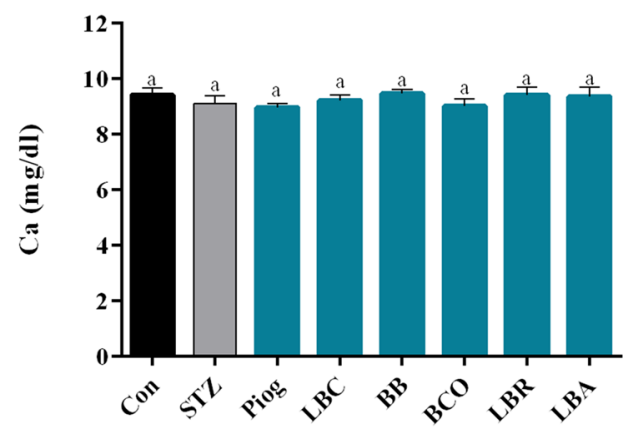

C

D
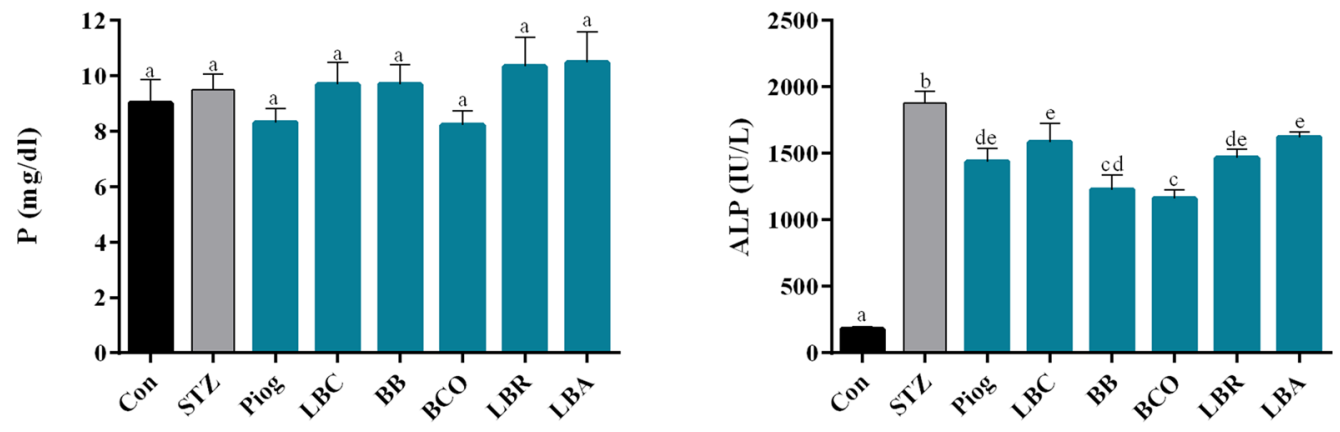

$\mathbf{E}$

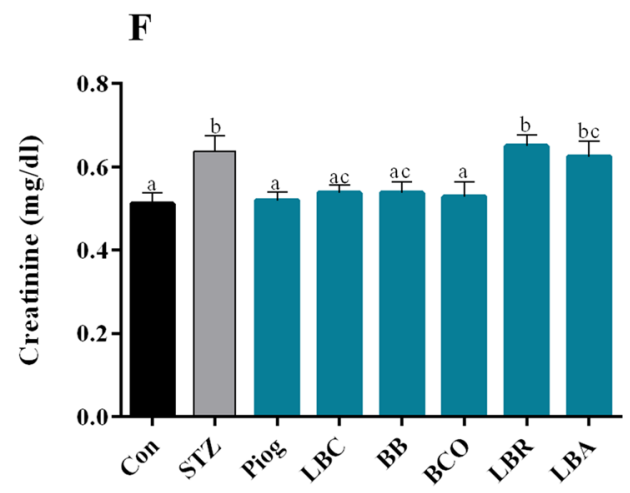

G

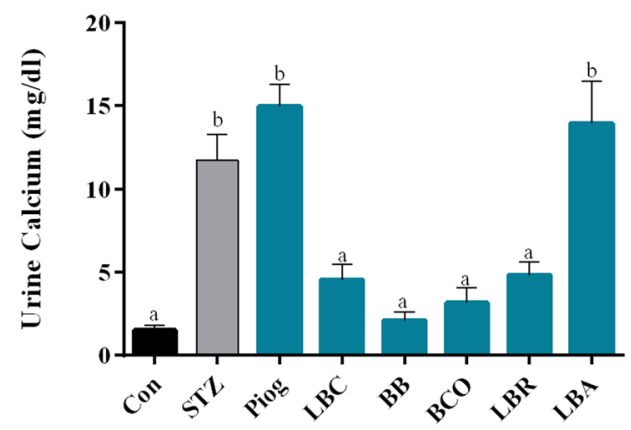

Fig. 1 The effect of probiotics on serum glucose (A), serum calcium (B), phosphorus (C), alkaline phosphatase (D) phosphorus, BUN (E), creatinine $(\mathbf{F})$, and urine calcium $(\mathbf{G})$ concentrations in rats during treatment with pioglitazone 


\section{Serum creatinine}

The STZ group showed significantly higher serum creatinine levels in comparison with the control group. The high level of serum creatinine was diminished in the pioglitazone, Bifidiobacter, Bacillus coagulans, and Lactobacillus casei groups. However, there was no change in the serum creatinine concentration in the Lactobacillus acidophilus and Lactobacillus reuteri groups compared to the STZ group (Fig. 1F).

\section{Urine calcium}

STZ, pioglitazone, and the combination of pioglitazone and Lactobacillus acidophilus significantly increased the urinary calcium level in contrast to the control group. Bifidobacteria, Bacillus coagulans, Lactobacillus casei, and Lactobacillus reuteri reduced the urinary calcium concentration to the average level, which was the same as the control group.

\section{Effects of probiotics on DEXA parameters}

Besides biochemical parameters, the impacts of probiotic strains on each DEXA outputs (BMD, BMC, and bone area) of global, femur, spine, and tibia were examined.

\section{Bone area}

The probiotics impacts on the global bone area of global, spine, femur, and tibia are revealed in Fig. 2. The outcomes exhibited that the global area was significantly reduced in the pioglitazone in contrast to the control group (Fig. 2A). Also, probiotics did not significantly improve the global area in the pioglitazone groups in contrast to the control group. In the case of spine-area (Fig. 2B), femur-area (Fig. 2C), and tibia-BMD (Fig. 2D), there were no significant variances between all groups.

\section{Bmc}

The impact of probiotics on the BMC of global, spine, femur, and tibia are displayed in Fig. 3. The pioglitazone group and STZ group exhibited significantly low global $\mathrm{BMC}$ in contrast to the control group. However, global BMC was notably ameliorated in all probiotics-treated groups in contrast to the pioglitazone group. The global$\mathrm{BMC}$ in the Bifidiobacter group was equal to the control group (Fig. 3A).

In the case of spine-BMC (Fig. 3B), no substantial variations were detected in STZ, pioglitazone, and probioticstreated groups compared to the control group. In respect to the femur- BMC (Fig. $3 \mathrm{C}$ ), similar to global BMC, the pioglitazone-treated group and STZ group displayed remarkably low global BMC compared to the control group. However, all the probiotics significantly enhanced the $\mathrm{BMC}$ in comparison with the pioglitazone groups and returned it to the normal level. In terms of tibia
BMC (Fig. 3D), there was a significantly decreased level in the pioglitazone treated group. All probiotic strains enhanced tibia BMC compared to the untreated pioglitazone group, which was only significant in the Bifidiobacter group. No significant changes were observed in terms of tibia BMC after probiotic supplementation, in contrast to the control group; however, probiotics were capable of returning the tibia $\mathrm{BMC}$ value to the average level after bone loss induced by pioglitazone.

\section{Bmd}

The impact of probiotics on the BMD of the global, spine, femur, and tibia are reported in Fig. 4. Pioglitazone significantly decreased the global-BMD compared to the control group, but all probiotic strains significantly enhanced global-BMD compared to the STZ and pioglitazone groups (Fig. 4A). For spine BMD (Fig. 4B), a similar trend was observed. No significant variance was spotted between probiotics-treated groups and the control group. Regarding femur BMD (Fig. 4C), all probiotics used in this study significantly increased the BMD compared to pioglitazone. In tibia BMD (Fig. 4D), despite the significant effect of probiotics on the BMD compared to the pioglitazone group, only Lactobacillus acidophilus and Bifidobacteria sp. revealed BMD as same as control group among the probiotics.

\section{Discussion}

This study, for the first time, provides some evidence about the protective effect of probiotic bacteria against pioglitazone-associated bone loss. In this research, we assessed the protective effects of Lactobacillus acidophilus, Lactobacillus reuteri, Lactobacillus casei, Bifidobacterium longum, and Bacillus coagulans on pioglitazone-induced bone loss in diabetic male rats. The results show that these probiotics, in combination with pioglitazone, can control blood glucose and improve BMD and bone quality.

Previously, a lot of clinical and preclinical researches have revealed that pioglitazone decreases trabecular bone volume, BMD, and BMC $[19,20]$. Therefore, it seems that this antidiabetic medicine (and the other insulin-sensitizing TZDs) can increase bone resorption and decrease bone formation by inhibiting osteoblast differentiation [21], specifically in post-menopausal women $[22,23]$. Consistent with previous significant works, this in vivo animal study indicated that pioglitazone had such an effect on the BMD and trabecular bone volume, which is associated with elevation of bone resorption and reduction of bone formation.

In a previous study, we revealed that some probiotic strains could increase the BMD, improve bone formation, reduce bone resorption, and change the microstructure 


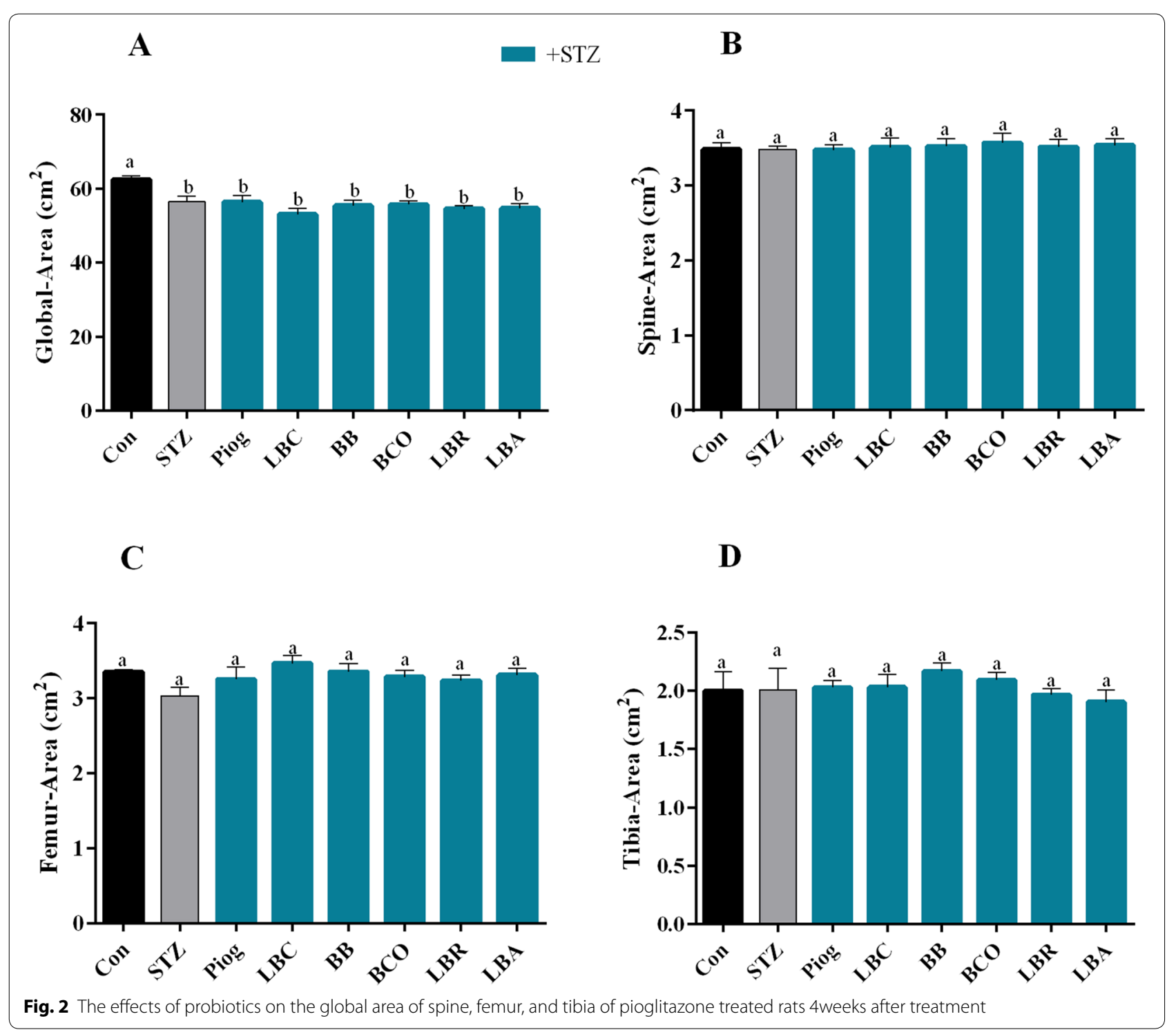

of the femur [16]. It appears that certain types of probiotic strains can play a role in GI microbiota restoration [24], enhancing the epithelial barrier [25], normalizing the immune responses [26], and facilitating the GI calcium absorption [27]. Therefore, these strains are useful in the prevention of bone resorption and may be useful for post-menopausal osteoporosis treatment [16]. In this study, we found declined BMD in the diabetic and pioglitazone-treated diabetic rats, which was in agreement with the earlier literature [28]. In the existing research, we also detected lower BMD in the diabetic groups in contrast to normal rats. Pioglitazone reduced BMD, especially in femur and tibia. The adverse effects of pioglitazone on femur-BMD was entirely reversed after treatment with all probiotics. The tibia-BMD loss caused by
STZ and pioglitazone was returned to the normal level, which was significant for Bifidobacterium longum and Lactobacillus acidophilus.

On the other hand, some clinical trials and meta-analysis studies indicated the beneficial effects of probiotic strains in T2DM [29-31]. Probiotics can ameliorate the glucose control in T2DM patients, and glycated hemoglobin level (which is a diagnostic indicator of blood glucose over the past 2 to 3 months) was decreased, representing an improvement in insulin resistance [32].

It has been suggested that the total body weight of diabetic patients is reduced due to proper blood glycemic control caused by probiotic intake. In addition, a general metabolic condition improvement was detected in the diabetic person following probiotic consumption 


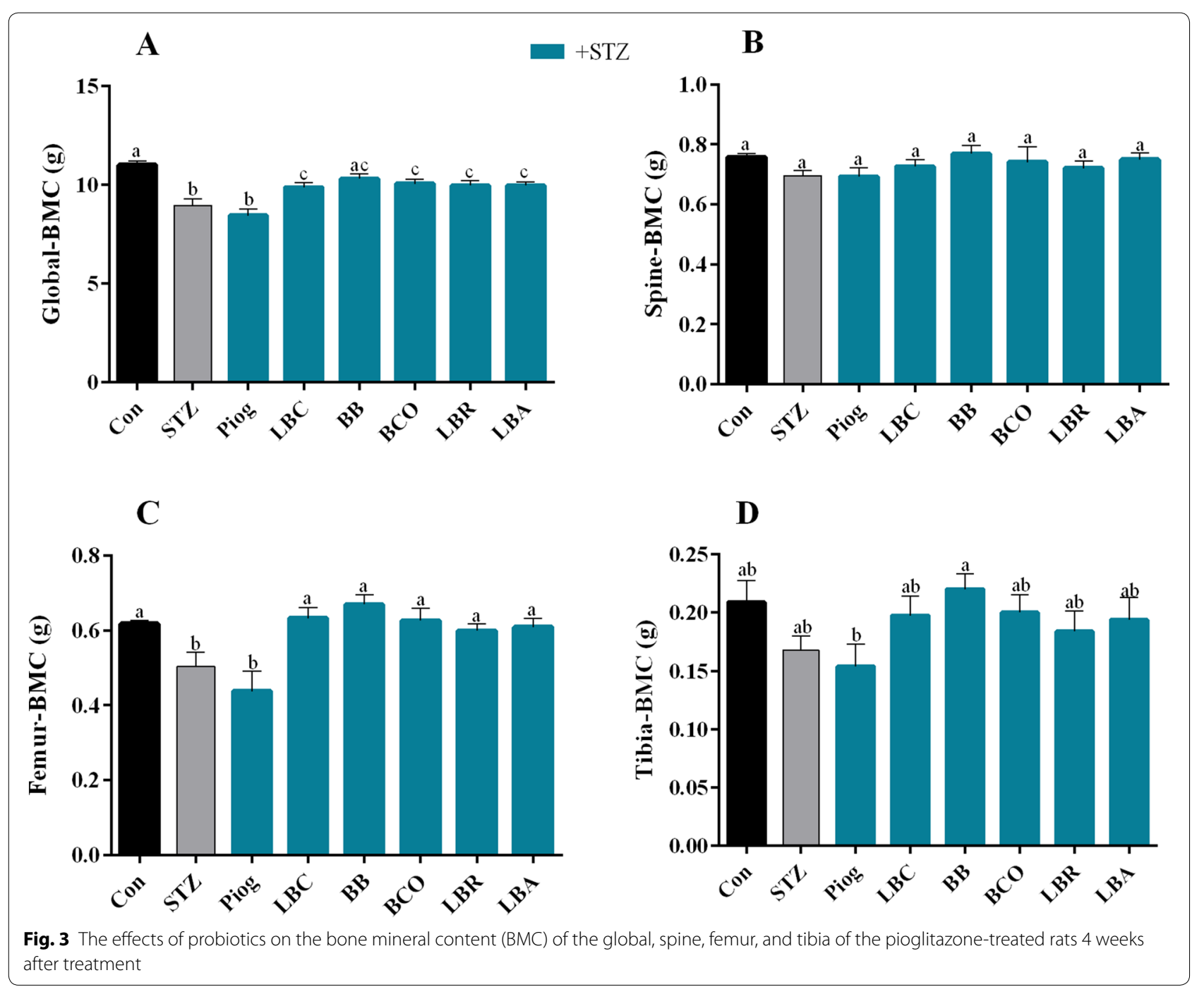

indicated by reduced triglyceride and C-reactive protein $[33,34]$. Overall, probiotics supplementation significantly reduced the fasting plasma glucose, glycated hemoglobin, fasting insulin, and homeostasis model assessment of insulin resistance in diabetic cases [29, 35, 36].

In the current study, we found that co-administration of probiotics and pioglitazone reduced the high glucose levels caused by STZ. The overall best combination therapy in controlling blood glucose without reducing calcium bone resorption has been shown in the animal group, which received Bifidobacterium longum and pioglitazone. A previous study showed that pioglitazone treatment did not affect serum calcium levels [37]. Similarly, no changes in serum calcium concentration in the pioglitazone group compared to the control group were found. Calcium excretion into urine was increased with pioglitazone, which was in accordance with Zanchi et al. study in which they examined the effects of pioglitazone on renal calcium excretion [38]. In addition, the results displayed that elevated urinary calcium excretion caused by STZ and pioglitazone was ameliorated after treatment with probiotics.

The mechanism by which probiotics exert their beneficial effect on bone health is not fully understood and seems to be very complicated because of the features of these organisms. Also, each probiotic strain produces different components affecting different pathways in the host's body. However, it is suggesting that there are some possible mechanisms for these bone protecting effects. First, their impact on the gut composition and media via adjustment of the intestinal $\mathrm{pH}$, production of biologically active peptides, and modification of the gut microflora have been shown $[15,39,40]$.

Second, the immunological aspect of probiotics has been mentioned in several studies. Many studies have reported that probiotic had anti-inflammatory effects, 


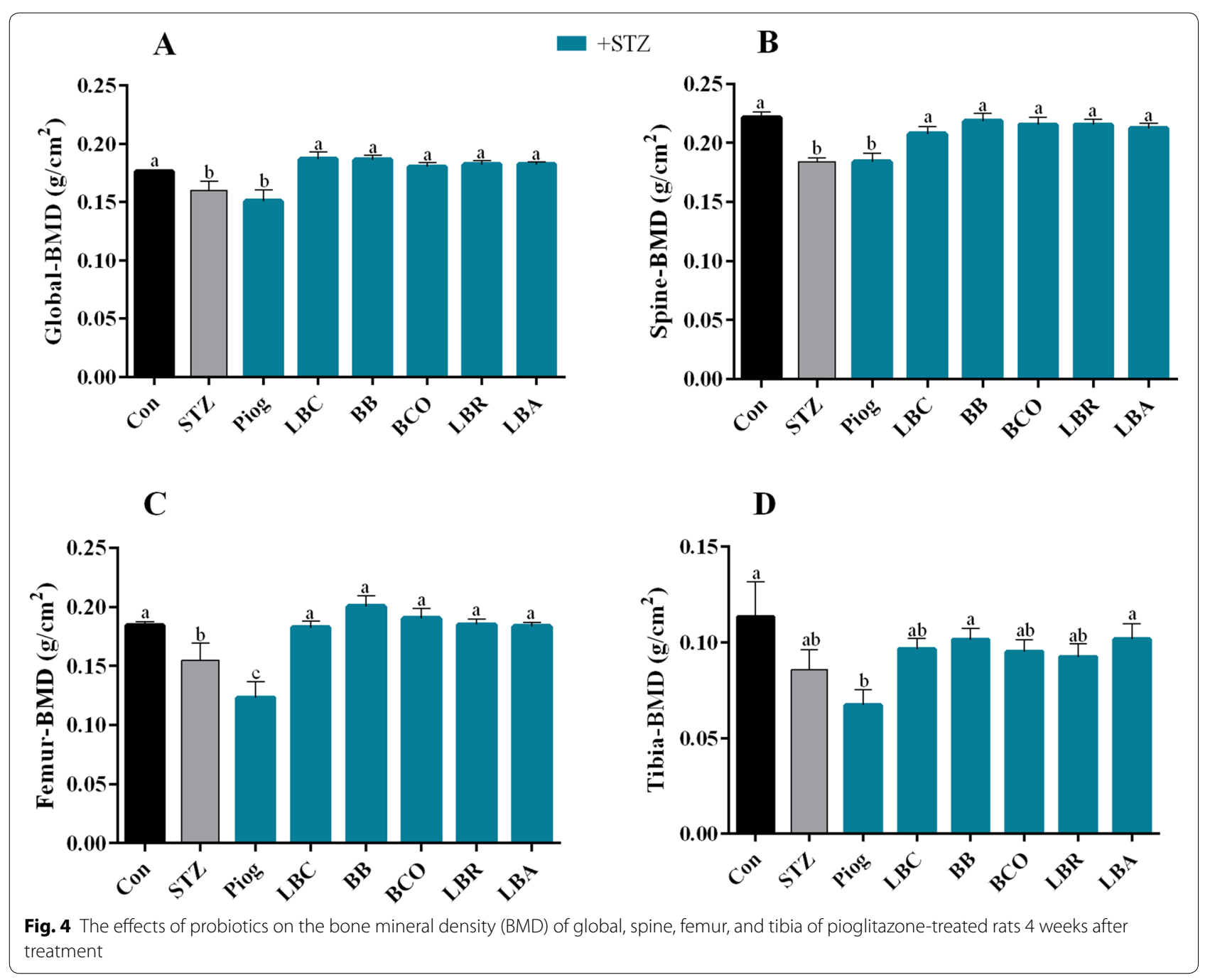

and they were already demonstrated to increase the regulatory $\mathrm{T}$ cells $[41,42]$ along with modulating Th17 cells differentiation and production [43]. It is proved that both Treg cells $(\mathrm{CD} 4+$ and CD8 +$)$ are correlated to mechanisms of bone protection [18]. Also, there is another nutritional possibility. Intestinal microbiota (e.g., probiotic bacterial strains) synthesize many proteins, enzymes, and vitamins, which are necessary for bone formation and growth, such as folic acid, vitamin D, K, and C [44]. It is primarily observed after the consumption of Bifidobacteria species [45]. Additionally, the genus Bifidobacteria can synthesize and secret short-chain fatty acids that can lower the luminal $\mathrm{pH}$ and helps the absorption of the minerals [46].

Among all probiotic strains used in this study, Bifidobacterium longum showed the best protective effect against osteoporosis induced by pioglitazone. It may be due to their additional protective effect on bone health in comparison to other probiotics. Bifidobacterium longum can decrease periodontal oxidative stress by modifying the NF-kB gene expression [47]. Reactive oxidative species can suppress osteoblast differentiation while enhancing osteoclast differentiation [48]. Thus, because of the potential effect of Bifidobacterium longum in stimulating osteoblastogenesis and inhibiting osteoclastogenesis, together with our experimental data, it is suggested that this strain can be used in combination with pioglitazone to prevent its bone loss effects in Type 2 diabetic patient.

There are some limitations to this study. First, the antiosteoporotic effects of probiotics in patients treated with pioglitazone based on clinical trials require further exploration. Second, an in-depth mechanism of probiotics effects on ameliorating pioglitazone-induced bone loss was not investigated. As a strength, this study, for the first time, provides some evidence about the protective effect of probiotics against pioglitazone-associated bone loss. Further, in vivo studies and clinical 
trials are recommended to be conducted to discover the vast aspects of this combination therapy and their mechanism.

\section{Conclusion}

Select probiotic strains, especially Bifidobacterium longum, increased the bone mass in the diabetesinduced rat model, and co-supplementation of probiotic with pioglitazone reduced the bone loss caused by pioglitazone. Therefore, co-administration of probiotic with pioglitazone as a clinical strategy is estimated to minimize bone loss and fracture risk in T2DM patients treated by pioglitazone.

\section{Supplementary information}

Supplementary information accompanies this paper at https://doi. org/10.1186/s13098-020-00587-3.

Additional file 1: Table S1. The physiological and biochemical characteristics of the selected isolates.

\section{Acknowledgements}

The authors would like to thank the Vice Chancellery of Shiraz University of Medical Sciences. Also, we would like to thank Dr. Nasrin Shokrpour for her editorial assistance.

\section{Authors' contributions}

AG contributed to conception and design, acquisition of data, drafting the manuscript and final approval of the manuscript; MHM contributed to conception and design and final approval of the manuscript, YG contributed to conception and design, and final approval of the manuscript; PT involved in the acquisition of data and analysis of data; FK contributed to conception and design, acquisition of data and analysis of data and final approval of the manuscript; NMN contributed to conception and design, acquisition of data, drafting the manuscript and final approval of the manuscript. All authors read and approved the final manuscript.

\section{Funding}

This study was supported by Shiraz University of Medical Sciences by the project number 97-01-33-18906.

\section{Availability of data and materials}

The datasets used and/or analyzed during the current study are available from the corresponding author on reasonable request.

\section{Ethics approval and consent to participate}

All animal experiments were in accordance with the National Institutes of Health guide for the care and use of laboratory animals (NIH Publications No. 8023, revised 1978) and approved by Ethical Committee of Shiraz University of Medical Sciences (97-01-33-18906).

\section{Consent for publication}

Not applicable.

\section{Competing interests}

The authors declare that they have no competing interests.

\section{Author details}

${ }_{1}$ Pharmaceutical Science Research Center and Department of Pharmaceutical Biotechnology, School of Pharmacy, Shiraz University of Medical Sciences, Shiraz, Iran. ${ }^{2}$ Endocrinology and Metabolism Research Center, Shiraz University of Medical Sciences, Shiraz, Iran.
Received: 31 May 2020 Accepted: 27 August 2020

Published online: 03 September 2020
References

1. Collaboration NCDRF. Worldwide trends in diabetes since 1980: a pooled analysis of 751 population-based studies with 4.4 million participants. Lancet. 2016;387(10027):1513-30.

2. Al-Goblan AS, Al-Alfi MA, Khan MZ. Mechanism linking diabetes mellitus and obesity. Diabetes Metab Syndr Obes. 2014;7:587-91.

3. Chawla A, Chawla R, Jaggi S. Microvasular and macrovascular complications in diabetes mellitus: distinct or continuum? Indian J Endocrinol Metab. 2016;20(4):546-51.

4. Valderrábano RJ, Linares MI. Diabetes mellitus and bone health: epidemiology, etiology and implications for fracture risk stratification. Clin Diabetes Endocrinol. 2018;4:9-10.

5. Vasudevan AR, Balasubramanyam A. Thiazolidinediones: a review of their mechanisms of insulin sensitization, therapeutic potential, clinical efficacy, and tolerability. Diab Technol Ther. 2004;6(6):850-63.

6. Tyagi S, Gupta P, Saini AS, Kaushal C, Sharma S. The peroxisome proliferator-activated receptor: a family of nuclear receptors role in various diseases. J Adv Pharm Technol Res. 2011;2(4):236-40.

7. Horii T, Iwasawa M, Kabeya Y, Shimizu J, Atsuda K. Investigating the risk of bone fractures in elderly patients with type 2 diabetes mellitus: a retrospective study. BMC Endocr Disord. 2019;19(1):81.

8. Aubert R, Herrera V, Chen W, Haffner S, Pendergrass M. Rosiglitazone and pioglitazone increase fracture risk in women and men with type 2 diabetes. Diabetes Obes Metab. 2010;12(8):716-21.

9. Zhu Z-N, Jiang Y-F, Ding T. Risk of fracture with thiazolidinediones: an updated meta-analysis of randomized clinical trials. Bone. 2014;68:115-23.

10. Loke YK, Singh S, Furberg CD. Long-term use of thiazolidinediones and fractures in type 2 diabetes: a meta-analysis. CMAJ. 2009;180(1):32-9.

11. Schwartz AV, Chen H, Ambrosius WT, Sood A, Josse RG, Bonds DE, et al. Effects of TZD use and discontinuation on fracture rates in ACCORD bone study. J Clin Endocrinol Metab. 2015;100(11):4059-66.

12. McDonough AK, Rosenthal RS, Cao X, Saag KG. The effect of thiazolidinediones on BMD and osteoporosis. Nat Rev Endocrinol. 2008;4(9):507-13.

13. Ruan Y, Sun J, He J, Chen F, Chen R, Chen H. Effect of Probiotics on Glycemic Control: A Systematic Review and Meta-Analysis of Randomized, Controlled Trials. PLoS One. 2015;10(7):e0132121-e.

14. Khalili L, Alipour B, Asghari Jafar-Abadi M, Faraji I, Hassanalilou T, Mesgari Abbasi M, et al. The Effects of Lactobacillus casei on Glycemic Response, Serum Sirtuin 1 and Fetuin-A Levels in Patients with Type 2 Diabetes Mellitus: a Randomized Controlled Trial. Iran Biomed J. 2019;23(1):68-77.

15. Collins FL, Rios-Arce ND, Schepper JD, Parameswaran N, McCabe LR. The Potential of Probiotics as a Therapy for Osteoporosis. Microbiol Spectr. 2017;5(4):https://doi.org/10.1128/microbiolspec.bad-0015-2016.

16. Montazeri-Najafabady N, Ghasemi Y, Dabbaghmanesh MH, Talezadeh P, Koohpeyma F, Gholami A. Supportive Role of Probiotic Strains in Protecting Rats from Ovariectomy-Induced Cortical Bone Loss. Probiotics and antimicrobial proteins. 2018:1-10.

17. Bayat M, Dabbaghmanesh MH, Koohpeyma F, Mahmoodi M, MontazeriNajafabady N, Bakhshayeshkaram M. The Effects of Soy Milk Enriched with Lactobacillus casei and Omega-3 on the Tibia and L5 Vertebra in Diabetic Rats: a Stereological Study. Prob Antimicrob Proteins. 2019;11(4):1172-81.

18. Dar HY, Shukla P, Mishra PK, Anupam R, Mondal RK, Tomar GB, et al. Lactobacillus acidophilus inhibits bone loss and increases bone heterogeneity in osteoporotic mice via modulating Treg-Th17 cell balance. Bone Rep. 2018;8:46-56.

19. Syversen U, Stunes AK, Gustafsson BI, Obrant KJ, Nordsletten L, Berge R, et al. Different skeletal effects of the peroxisome proliferator activated receptor (PPAR)alpha agonist fenofibrate and the PPARgamma agonist pioglitazone. BMC Endocr Disord. 2009;9:10-.

20. Vianna AGD, Sanches CP, Barreto FC. Review article: effects of type 2 diabetes therapies on bone metabolism. Diab Metab Syndrome. 2017;9(1):75 
21. Wei W, Wan Y. Thiazolidinediones on PPARY: The Roles in Bone Remodeling. PPAR Res. 2011;2011:867180-.

22. Schwartz AV. TZDs and Bone: A Review of the Recent Clinical Evidence. PPAR Res. 2008;2008:297893-.

23. Falchetti A, Masi L, Brandia ML. Thiazolidinediones and bone. Clin Cases Miner Bone Metab. 2007;4(2):103-7.

24. Azad MAK, Sarker M, Li T, Yin J. Probiotic Species in the Modulation of Gut Microbiota: An Overview. Biomed Res Int. 2018;2018:9478630-.

25. Xu X, Jia X, Mo L, Liu C, Zheng L, Yuan Q, et al. Intestinal microbiota: a potential target for the treatment of post-menopausal osteoporosis. Bone Res. 2017;5:17046-

26. Manuel PM, Elena B, Carolina MG, Gabriela P. Oral probiotics supplementation can stimulate the immune system in a stress process. J Nutri Intermediary Metab. 2017;8:29-40.

27. Parvaneh $K$, Jamaluddin R, Karimi G, Erfani R. Effect of probiotics supplementation on bone mineral content and bone mass density. ScientificWorldJournal. 2014;2014:595962-.

28. Adil M, Mansoori MN, Singh D, Kandhare AD, Sharma M. Pioglitazoneinduced bone loss in diabetic rats and its amelioration by berberine: $\mathrm{A}$ portrait of molecular crosstalk. Biomedicine \& pharmacotherapy $=$ Biomedecine \& pharmacotherapie. 2017;94:1010-9.

29. Kasińska MA, Drzewoski J. Effectiveness of probiotics in type 2 diabetes: a meta-analysis. Polish Archives Internal Med. 2015;125(11):803-13.

30. Panwar H, Rashmi HM, Batish VK, Grover S. Probiotics as potential biotherapeutics in the management of type 2 diabetes-prospects and perspectives. Diab Metab Res Rev. 2013;29(2):103-12.

31. Ejtahed H, Mohtadi-Nia J, Homayouni-Rad A, Niafar M, Asghari-Jafarabadi M, Mofid V, et al. Effect of probiotic yogurt containing Lactobacillus acidophilus and Bifidobacterium lactis on lipid profile in individuals with type 2 diabetes mellitus. J Dairy Sci. 2011;94(7):3288-94.

32. Tonucci LB, dos Santos KMO, de Oliveira LL, Ribeiro SMR, Martino HSD. Clinical application of probiotics in type 2 diabetes mellitus: a randomized, double-blind, placebo-controlled study. Clin Nutr. 2017;36(1):85-92.

33. Yao K, Zeng L, He Q, Wang W, Lei J, Zou X. Effect of Probiotics on Glucose and Lipid Metabolism in Type 2 Diabetes Mellitus: a Meta-Analysis of 12 Randomized Controlled Trials. Med Sci Monit. 2017;23:3044-53.

34. Koutnikova H, Genser B, Monteiro-Sepulveda M, Faurie J-M, Rizkalla S, Schrezenmeir J, et al. impact of bacterial probiotics on obesity, diabetes and non-alcoholic fatty liver disease related variables: a systematic review and meta-analysis of randomised controlled trials. BMJ Open. 2019;9(3):e017995.

35. Mazloom Z, Yousefinejad A, Dabbaghmanesh MH. Effect of probiotics on lipid profile, glycemic control, insulin action, oxidative stress, and inflammatory markers in patients with type 2 diabetes: a clinical trial. Iranian J Med Sci. 2013;38(1):38.
36. Zhang $Q$, Wu Y, Fei X. Effect of probiotics on glucose metabolism in patients with type 2 diabetes mellitus: a meta-analysis of randomized controlled trials. Medicina. 2016;52(1):28-34.

37. Kanda J, Izumo N, Kobayashi Y, Onodera K, Shimakura T, Yamamoto N, et al. Effect of the antidiabetic agent pioglitazone on bone metabolism in rats. J Pharmacol Sci. 2017;135(1):22-8.

38. Zanchi A, Pechere-Bertschi A, Burnier M, Bonny O. Effects of pioglitazone on renal calcium excretion. J Clin Endocrinol Metab. 2011;96(9):E1482-5.

39. Cerdó T, García-Santos JA, G Bermúdez M, Campoy C. The Role of Probiotics and Prebiotics in the Prevention and Treatment of Obesity. Nutrients. 2019;11(3):635.

40. Pickard JM, Zeng MY, Caruso R, Núñez G. Gut microbiota: role in pathogen colonization, immune responses, and inflammatory disease. Immunol Rev. 2017;279(1):70-89.

41. Fu L, Peng J, Zhao S, Zhang Y, Su X, Wang Y. Lactic acid bacteria-specific induction of CD4 + Foxp3 + T cells ameliorates shrimp tropomyosininduced allergic response in mice via suppression of mTOR signaling. Sci Rep. 2017;7(1):1987.

42. Zhao H-M, Huang X-Y, Zuo Z-Q, Pan Q-H, Ao M-Y, Zhou F, et al. Probiotics increase $T$ regulatory cells and reduce severity of experimental colitis in mice. World J Gastroenterol. 2013;19(5):742-9.

43. Owaga E, Hsieh R-H, Mugendi B, Masuku S, Shih C-K, Chang J-S. Th17 Cells as Potential Probiotic Therapeutic Targets in Inflammatory Bowel Diseases. Int J Mol Sci. 2015;16(9):20841-58.

44. Crittenden RG, Martinez NR, Playne MJ. Synthesis and utilisation of folate by yoghurt starter cultures and probiotic bacteria. Int J Food Microbiol. 2003:80(3):217-22.

45. Arunachalam KD. Role of bifidobacteria in nutrition, medicine and technology. Nutr Res. 1999;19(10):1559-97.

46. Campbell JM, Fahey GC Jr, Wolf BW. Selected indigestible oligosaccharides affect large bowel mass, cecal and fecal short-chain fatty acids, ph and microflora in rats. J Nutri. 1997;127(1):130-6.

47. Tomofuji T, Ekuni D, Azuma T, Irie K, Endo Y, Yamamoto T, et al. supplementation of broccoli or Bifidobacterium longum-fermented broccoli suppresses serum lipid peroxidation and osteoclast differentiation on alveolar bone surface in rats fed a high-cholesterol diet. Nutri Res. 2012;32(4):301-7.

48. Manolagas SC. From estrogen-centric to aging and oxidative stress: a revised perspective of the pathogenesis of osteoporosis. Endocr Rev. 2010;31(3):266-300

\section{Publisher's Note}

Springer Nature remains neutral with regard to jurisdictional claims in published maps and institutional affiliations.
Ready to submit your research? Choose BMC and benefit from:

- fast, convenient online submission

- thorough peer review by experienced researchers in your field

- rapid publication on acceptance

- support for research data, including large and complex data types

- gold Open Access which fosters wider collaboration and increased citations

- maximum visibility for your research: over $100 \mathrm{M}$ website views per year

At BMC, research is always in progress.

Learn more biomedcentral.com/submissions 